\title{
Design Research to Support Fourth Grader Learn Addition of Mixed Numbers in RME Learning
}

\author{
Hening Windria ${ }^{{ }_{1}}$, Zulkardi Zulkardi², Yusuf Hartono ${ }^{2}$ \\ 1 Universitas Negeri Semarang, Semarang, Indonesia \\ 2 Universitas Sriwijaya, Palembang, Indonesia \\ $\bowtie$ hwindria@gmail.com
}

\begin{abstract}
Mixed numbers and fraction in general have been a problem for students not only in understanding the concept of itself, but also in understanding the operation of it, such as addition. Thus, supporting students in learning addition of mixed numbers is needed. the aim of this study is to develop a local instructional theory and materials related to supporting students in learning addition mixed numbers. In order to develop the theory, this study used design research method. The is collected by generating the video recording of the learning process, student's written work, students' result from pretest and posttest, the result of interview, and also the fields note from the observation. The participants of this study are fourth grade students in one of private elementary school in Palembang. From the study, it can be seen that students have built the reasoning in addition mixed numbers. Some of them are able to use the distribution principle and use equivalence fractions when they adding the mixed numbers, and some of them are directly used the algorithm of changing mixed number to improper fractions. However, it is insufficient to say that the fractions number line has a big role in the students' finding.
\end{abstract}

Keywords: addition of mixed numbers, design research, mixed numbers, number line, realistic mathematics education

How to Cite: Windria, H., Zulkardi, Z., \& Hartono, Y. (2020). Design Research to Support Fourth Grader Learn Addition of Mixed Numbers in RME Learning. Mimbar Sekolah Dasar, 7(1), 153-170. doi:https://doi.org/10.17509/mimbar-sd.v7il.23978.

INTRODUCTION Fractions have an important part in mathematics. One of the importance is that the role of fractions in algebraic reasoning. According to Norton \& Wilkins (2013) students need to understand fractions concept before they are able to do manipulation of the variables in algebraic expressions in algebraic equations. this is related to the interpretation of fractions. Fractions have many interpretations. Bruce et al (2013) list at least there are five interpretations of fractions. Those interpretations are linear interpretation, part-whole interpretation, part-part interpretation (ratio), quotient interpretation, and also as operator. These interpretations make fractions confusing. Thus, according to Moseley and Okamoto (as cited in Norton \& Wilkins: 2013) most students are not able to develop the understanding of this multiple interpretations of fractions.

Despite this, simple fractions are used in daily life, such as halves and quarters. The practice of using fractions can be related to not only as part of a thing, such as half of oranges, or three quarters of cake, but also a measurement result such as half kilograms of flour, or one and half 
Hening Windria et al., Design Research to Support Fourth Grader Learn Addition ...

meters of fabric. This latter measurement results has a different terms in mathematics. The term for numbers 'one and half' is mixed numbers. Some might call it mixed fractions. However, the terms that is used in this study is mixed numbers. Thus, a number can called a mixed numbers is when a number consists of an integer and a fraction such as one and half or $1 \frac{1}{2}$ in mathematical symbol (Tanton, 2005).

There are a lot of studies that learnt about fractions. This is related to difficulty that the students face when learning it. There are three main reason of this situation. Firstly, even if students find fractions in their daily life, they are not able to relate it to the fractions they learn in classroom situation (Keijzer, 2003). Secondly, students have the difficulty in understanding the meaning of the mathematical symbols of fractions (Thomson \& Saldanha, 2003). Thus, it is understandable that students mix up the fractions as natural numbers when they add two fractions (Idris \& Narayanan, 2011; Izsák, Tillema, \& Tunç-Pekkan, 2008;). For example, instead of doing $\frac{1}{2}+\frac{1}{3}=\frac{5}{6}$, students might do $\frac{1}{2}+\frac{1}{3}=\frac{2}{5}$. Students directly adding the number in denominator and numerator. The last, students might find that there are many rules and algorithm in fractions that confusing for them. Just as Lestiana, Rejeki and Setyawan (2017) found that some students that did not able to do the addition of fractions, just applied any algorithm that familiar for them.

Those three main reasons of the difficulty of learning fractions are very likely also happen when students learn about mixed numbers. First, students also have a difficulty in understanding of the meaning of the mixed numbers' symbols (Saxe et al., 2005).. It is related to the meaning of the mixed numbers where $5 \frac{1}{3}=5+\frac{1}{3}$ that is not the same as the meaning of $a b=a \times b$ in algebra. Additionally, the form of mixed numbers could also confusing for students when they think the integer part of the mixed numbers as a fractions also, for instance when doing subtraction $2-\frac{3}{8}$, some students might treat 2 not as integer, but as fractions also (Saxe et al., 2005). Thus, instead of $1 \frac{5}{8}$ or $\frac{13}{8}$, students can get $-\frac{1}{8}$. Then, regarding to the algorithm, there are two ways when dealing with the mixed numbers according to the textbook of department mathematics in College of Redwood (2012), especially addition and subtraction of it. First, by changing the mixed numbers into improper fractions, and operating as those afterwards. Second, by adding or subtracting each part of mixed numbers by the same part. for example to add 2 and a quarter by 1 and a quarters, first add the integer, 2 and 1 , and then add the fractions, a quarter and a quarter. Thus, the result will be 3 and two quarters.

Reminded that learning fractions is not an easy matter for students, a question is arising, how can a teacher help the students learning mixed numbers? Since this questions is rather broad, then in this paper the learning scope will be narrowed to learning the addition of mixed 
numbers. Still, questions are lingering. How teacher can help students learn addition mixed numbers, what instructional theory can be used.

One of instructional theory that can used is Realistic Mathematics Education (RME) that is developed in Netherlands. However, since this study is conducted in Indonesia, instead of RME, the instructional theory that will be used is Pendidikan Mathematika Realistik Indonesia (PMRI) - Indonesian Realistic Mathematics Education. The main reason of this choice is not only to implement the alternative methods of teaching and learning, but also to achieve social transformation within Indonesia (Sembiring et al., 2008). To be precise, PMRI in Indonesia serves as a movement to reform the paradigm in teaching and learning mathematics in Indonesia Classrooms.

According to Treffers (as cited in Zulkardi, 2002), there are five tenets in RME. Those tenets are use of context (concreteness), the use of models, the use of students' own productions and contributions, the interactive character in the teaching process, and the intertwining of various mathematics units. Thus, since this study use PMRI, Indonesian version of RME, the lesson designed in this study will abide this tenets also.

There are several models that can be used in learning fractions, hence mixed numbers. According to Fosnot and Dolk (2002), to learn fractions the model that can be used are a bar, an array, a number line, a double number line, and a ratio table (see Figure 1). Beside this models, there still model of area that is use to learn fractions see (see Figure 1). Moreover, according to Saxe et al. (2007) this model can give a disadvantage to students in a sense that students will more rely on the number of the part than the relation between parts. Saxe et al. (2007) propose to use the number line to help the students in learning fractions. Therefore, for this study, number line is chosen to help students learn as Saxe suggested. Moreover, this model is related to the measuring activities that will be used in this study as the context of the activity in learning fractions
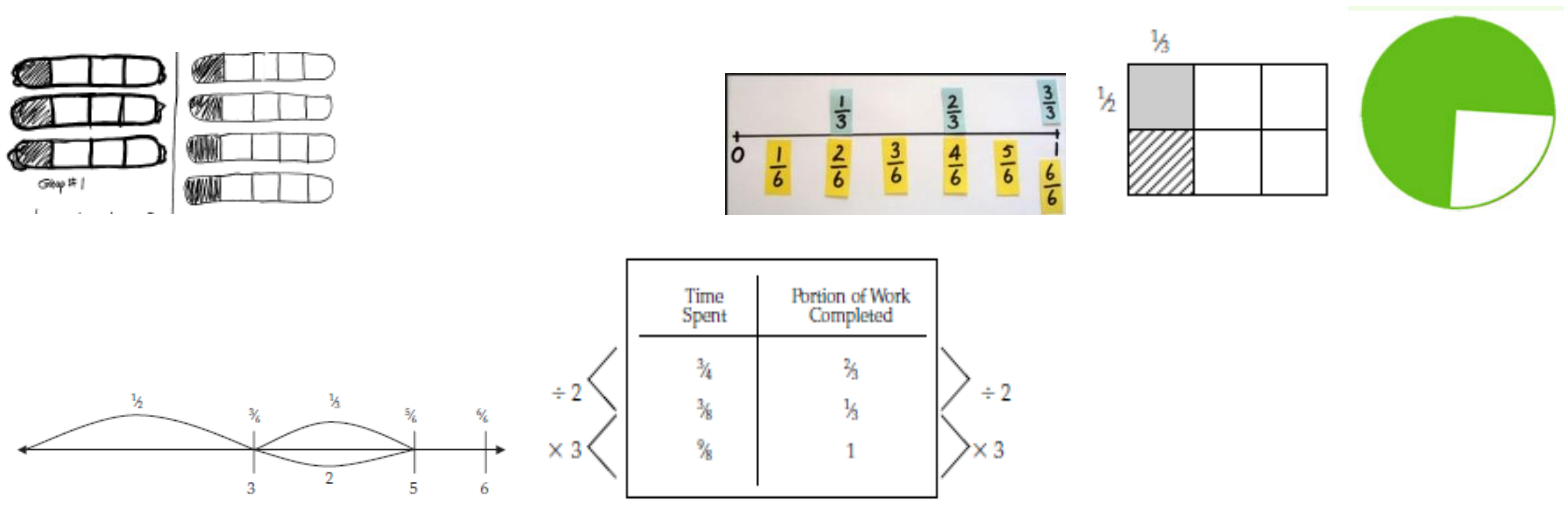

Figure 1. Examples of model that used in learning fractions. The model from above left corner to below right corner are bar modelling, a number line, an array, an area model a double number line, and a ratio table 
Hening Windria et al., Design Research to Support Fourth Grader Learn Addition ...

Generally, the purpose of this paper is to develop a local instructional theory and materials related to supporting students in learning addition mixed numbers. Local instructional theory is a theory about the process of students' learning in certain topic in mathematics and also theories about how to support the learning process (Gravemeijer \& van Eerde, 2009). Additionally, the model that will be used in learning is the number line. Thus, the question formulated is How can the use of fraction number line supports students in learning addition of mixed numbers?

\section{METHOD}

\section{Research Approach}

This study used design research as the approach of the research. The reason choosing thus approach is that the approach have similar aims as this study in which to generating new theories (Edelson, 2002). Other reasons to choose design research are the design research provides a productive perspective for theory development, design research provide the useful results, such as design of investigations or sequence of learning and The last, design research directly involves researchers in improving education (Edelson, 2002). The aim of this study is to develop a Local Instructional Theory (LIT) that consists of how the students' learning proceeds and what the support that can be given. Specifically, this study focused on the addition of mixed numbers.

As a research methods, design research has several characteristics. One of the characteristics that essential is the cyclic character (Eerde, 2013). The illustration of this characteristic can be seen in Figure 2 below.

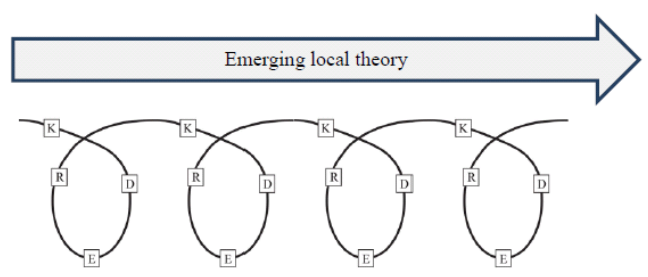

Figure 2. cyclic process in the design research (Eerde, 2013)

In general, the cycle is started by researching the needed knowledge (K). Afterwards, from the theory and knowledge, the designing process is taken place (D). The design in this study consists of designing learning sequence and Hypothetical Learning Trajectory (HLT). Afterwards, the design is experimented in the teaching experiment to see what students really think and how the understanding are evolved in the classroom (E). The next steps, is the retrospective analysis (R) where researcher will reflect on the data of the experiment. In the analysis, the HLT is used as the guideline. Moreover, the aim of the analysis is to refine the HLT designed initially. This HLT later on is used as the base knowledge for the next cycle. 
This article is part of the bigger study in learning addition mixed numbers. Thus, not all of part of the study is presented. In the bigger study there are two cycle and five meetings in each cycle. However, this article only focused on the third meeting. The reason of this is that in meeting three students start to learn about the addition mixed numbers. Additionally, there is a little changes in HLT in the initial design (for cycle 1) and the refine version (for cycle 2). Thus, there are no big changes in the activity and the worksheet. More importantly, this meeting is an important part for students to build their knowledge in learning addition of mixed numbers.

Regarding the context used throughout the lesson is related to the length or distance. It is related to one of the five interpretation of the fractions according to Bruce et al. (2013) that is linear measurement. The reason behind this context is that it is tightly related to the model that is used to help students in the lesson, the fraction number line. Furthermore, in the lesson the symbols of mixed numbers, the definitions, and also mathematical terms used students own term.

\section{Participants}

This study involves 4 students in the first cycle while in the second cycle, this study involves 30 students and their teacher. All of the students are fourth-grader from one of private elementary school in, Palembang. Later on, students from cycle 1 will be coded as student $1 a$, student $1 b$, student $1 c$, and student $1 d$. Students from cycle 2 will be coded as students $2 a$, students $2 b$, and so on.

\section{Collecting and Analyzing the Data}

The data collected in this study came from interview, students' written work, video recording, and field note. The data is collected in pretest, posttest, interview of students, and also learning process.

The data analyzed by comparing what happen in the classroom and the conjecture in the HLT. Thus, the HLT is used as the guidelines of the analysis (Bakker \& van Eerde, in press). The analysis is conducted by descriptive analysis.

\section{Validity and Reliability}

The concept of internal validity is related to what extends the finding of this study is believable and trustworthy (Denscombe, 2010)_. In order to increase this quality, this study use data triangulation or use multiple source of data, namely video recordings of the lesson, students' written works, teacher's interview, and field note.

The concept of internal reliability in this study refers to the independency of researcher towards the data taken. It means that the researcher will not affect the gathering data process 
Hening Windria et al., Design Research to Support Fourth Grader Learn Addition ...

(Denscombe, 2010). In order to have a good reliability, the data taken by using video camera and the transcript of the video is also made in order to ensure the independency.

\section{Hypothetical Learning Trajectory of Meeting Three}

As mention that this study only focused on the third meeting. Here will be explained the the condense version of the HLT for third meeting This HLT consists of the learning goal of the meeting, the starting point, description of the activity, and also the conjecture of students thinking (Simon \& Tzur, 2004).

\section{Goals}

On one hand, the main learning goals of the meeting is that students are able to reason what happen to the mixed numbers in addition operation. On the other hand, the goals of the activity are that students are able to find the right measurement strips needed to be used in the task, and to find the result of the addition of mixed numbers.

\section{Starting point}

According to the their teacher, students in the first cycle have not learned yet about the addition of mixed numbers and even they have not learned the addition of fractions that have different denominator. Furthermore, it can be seen in the students' written work (see Figure 3a3c). Two of the students were not able to solve the problem that related to addition of mixed numbers appropriately, while one of students was not able to solve addition of fractions.

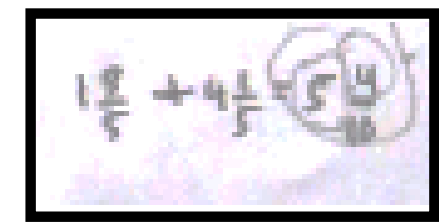

Figure 3a. student 1b's work

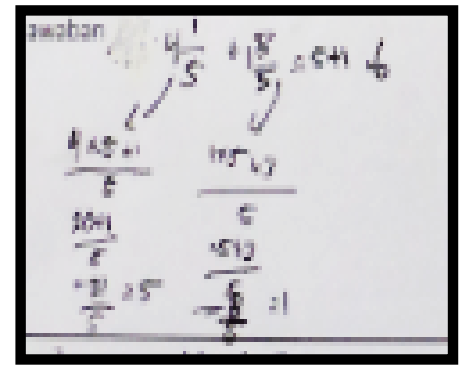

Figure 3b. student lc's work

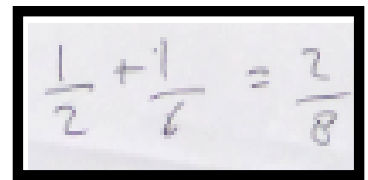

Figure 3c. student 1d's work 
It can be seen from Figure $3 a$ that students $1 b$ only adding the numbers in the problems without any regards to the mixed numbers. A little different from students $1 b$, students $1 c$ is seems as if she was able to solve the problem by changing the mix numbers to improper fractions. However, since she only know the algorithm of changing the mixed numbers, she did the mistake in dividing the fractional part. For students $1 d$, it's clear that she did not have any idea of the addition of fractions. When asked where the result come from, she indicated that she just add the numbers accordingly. Additionally, when the students of this first cycle is asked where did they know the algorithm in solving addition of fractions or changing the mixed numbers into fractions, they just shrugged their shoulder. Thus, it can be said that students are learning by memorizing the algorithm given without any understanding in it.

Differ from the first cycle students, the students from the second cycle have already learnt addition of fractions that have different denominator yet to learn the addition mixed numbers yet though. Some students were able to solve the problems regarding addition mixed numbers get the lesson in their additional course outside of the school, some are able to solve it by changing the mixed numbers into improper fractions.

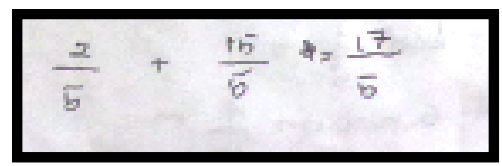

Figure 4a. student 2a's work

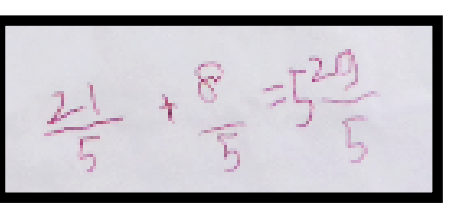

Figure 4b. student 2b's work

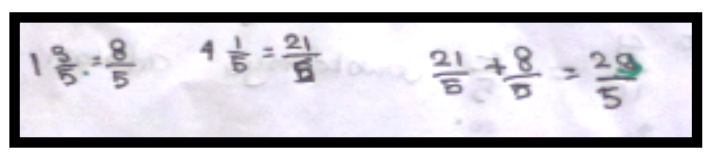

Figure 4c. student 2c's work

$$
\frac{21}{5} d+\frac{8}{5} \quad \frac{105}{25}+\frac{40}{25}=\frac{45}{25}
$$

Figure 4d. student 2d's work

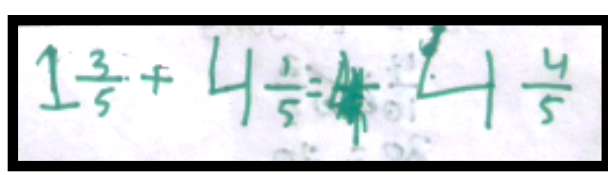

Figure 4 e. student $2 e$ 's work

The Figure above shows the Figure of students' written work in solving problem regarding addition of mixed numbers. In the problem, in order to solve it, students have to add $1 \frac{3}{5}$ quintal of rice with another $4 \frac{1}{5}$ quintal of rice. It can be seen that the students' have two ways of 
Hening Windria et al., Design Research to Support Fourth Grader Learn Addition ...

solving, changing the mixed numbers (see Figure $5 a-5 d$ ) and directly add the numbers (see Figure $5 e)$. However, some of these students are unable to solve the addition appropriately.

One of the students, student $2 a$, even make a mistake in changing the mix numbers into improper fractions (see Figure $5 \mathrm{a}$ ). It is possibly happen because student $2 a$ only learned the changing algorithm by memorizing the algorithm taught. Additionally, in the interview she said a completely different algorithm and mix up the algorithm of the interchanging of mixed numbers and improper fraction.

Over all, most of students in this second cycle are able to perform the formal algorithm of solving addition of fractions. However, some of them still perform an improper algorithm. When solving addition of mixed numbers, some of the students already try using the algorithm they have, changing the mixed numbers to improper fractions and addition of fractions, to solve the mixed numbers problem.

\section{Description of the activity}

In this meeting 3, the students for the first time will face the addition of mixed numbers. The problem is 'Andy want to make a new records that consist of the total length of the same color ribbon. This is the list that Andy has

\begin{tabular}{|l|c|}
\hline $\begin{array}{c}\text { Color of the } \\
\text { ribbon }\end{array}$ & The length of two ribbons \\
\hline (red) & $\frac{1}{2}$ strip dan 1 strip \\
\hline (vellow) & 1 strip dan $1 \frac{3}{8}$ strips \\
\hline (green) & $2 \frac{1}{4}$ strips dan $1 \frac{1}{4}$ strips \\
\hline (pink) & $2 \frac{1}{4}$ strips dan $\frac{1}{2}$ strips \\
\hline & $1 \frac{1}{4}$ strips dan $1 \frac{3}{8}$ strips \\
\hline
\end{tabular}

Figure 5. the Figure of the table of ribbon size lists

To solve the addition of the mixed numbers, students are provided several size paper strips and blank fraction number line (see figure 8). Some strips are the appropriate size of the ribbons, while some are not.

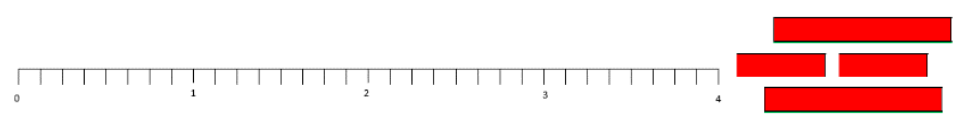

Figure 6. example of fraction ruler (above) and paper strips (below) used in the activity After students found the total length of the ribbons, the next activity is the discussion in which students will see what happen to the mixed numbers in the addition operation. The addition problem that is discussed is the last problems, namely $1 \frac{1}{4}+1 \frac{3}{8}=2 \frac{5}{8}$.

The Conjecture 
The conjecture is constructed according to the theory about fractions (such as the meaning of fractions and mixed numbers, students difficulty in learning fractions and mixed numbers, addition of mixed numbers), brainstorming with teacher and fellow colleagues. It also validated by the supervisor of the research. Below are the conjecture of what students might do in the activity.

In finding the strips

1. Some students find the appropriate strips by measuring the length of the strips using the fraction ruler.

2. Some students find the strips by taking two strips that likely to be the appropriate one.

3. Some students not find the appropriate strips.

In finding the result

1. Students are able to find the result by pasting the appropriate strips above the fractions ruler provided.

2. Some students are unable to find the correct result since they did not find the appropriate strips.

3. There are two ways of students in completing the fraction ruler

a. Students write all the mixed numbers correctly in the appropriate mark

b. Students only write the needed mixed numbers, referring to the problems

c. Students only write the mixed numbers that is the final result of the problem.

In reasoning

1. Students are able to use equivalence reasoning when explaining what had happen to the mixed numbers

2. Some students might use formal algorithmic reasoning to explain.

\section{RESULTS AND DISCUSSION}

\section{First Cycle Students' Answer}

In solving this problem, the students are divided into two groups, student $1 \mathrm{a}$ with student $1 \mathrm{~b}$ and student $1 \mathrm{c}$ with student $1 \mathrm{~d}$. Using the fraction ruler and paper strips, students in the first cycle do not have a difficulty in finding the final answer. Nevertheless, this both groups solve the problem in different speed, group 1 (student la and lb) is faster than the other group. The second group spends more time in finding the strips and also writing down all the part in the number line. The difference in the answer of both group can be seen below.

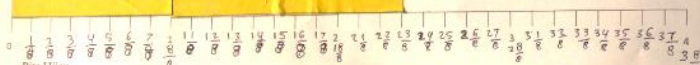


Hening Windria et al., Design Research to Support Fourth Grader Learn Addition ...

Figure 7. Both groups answer in one of the problem provided in the activity

From Figure 7 above, it can be seen that students have different approach in using fraction ruler. Group 1 is able to find a certain length in fraction ruler without completing the number line, while the second group have to complete the fraction ruler in order to find the length of the strip. Apart from this difference, both group are able to find the result of the addition of mixed numbers.

The important part of this meeting is the discussion in which students will discuss what have happen to the numbers in the addition of mixed numbers. From five addition problems, the last problem, $1 \frac{1}{4}+1 \frac{3}{8}=2 \frac{5}{8}$ is chosen to open the discussion. In the discussion, students struggle with what happen to the fraction part in the mixed numbers. Fragment 1 below shows the struggle the students have face in finding their reasoning.

Fragment 1 first cycle students' struggling

1. Researcher : can anybody give an explanation?

2. Student $1 d$ : I can(enthusiasticly and suddenly raise her hand), but how can the result is 5 ? (refer to the nominator of the result).

3. Student $1 \mathrm{~b}$ : it should be 3 plus 1 . (refer to the nominator of fractions in the problem)

4. Student $1 d$ : yeah.. (students 1 nodding her head). how come?

5. Researcher : let see the denominator

6. Student 1d: oh the denominator is 8 plus eh ... (scratching her head)

7. (students keep thinking and struggling, after a while one of the students are able find the reason of the addition mixed numbers and what happen to the numbers)

8. Researcher : is there anyone else that can explain why this can happen?

9. Student la: (stand up) oh yo $1 / 4$ is changed into ... hmm

10. Student $1 d: 5 / 8$ ?

11. Student la: no..it became 2/8.

12. Researcher : $1 / 4$ is changed into $2 / 8$. so, is there any questions?

13. (Researcher write down the changing of the fractions)

14. Researcher: so, $12 / 8+13 / 8$, what is the result?

15. Student $1 a$ : ooh... the result is $25 / 8$. (confidently)

16. Student 1d: (after a while and thinking what is written in the explanations) oooh that's right From the fragment above it can be seen that students are facing a different situation in addition of fractions and addition of natural numbers (refer to line 2-4). By the end of the discussion, students will build an understanding that addition in fractions different from the addition in natural numbers. Later, in the discussion students find out that one of the fractions are substitute by the equivalence of it or the other name of the fractions. In the previous 
meeting, students from cycle 1 have already learnt that fractions have many name (read, equivalence). This 'other name' term are easier to use by students.

The further result of this meeting is that students are able to find the addition of mixed numbers using direct addition of integer and fractions part in the mixed numbers. Moreover, for the fractions that have a different but friendly denominator students are able to change the fractions to its equivalence in order to solve the addition of mixed numbers. Figure 10 below shows some of students' written work after this meeting.

$$
5 \frac{1}{9}+1 \frac{3}{8}=5 \frac{2}{8}+1 \frac{3}{8}=6 \frac{5}{8}
$$

Figure 9a. students 1a's written work in the activity

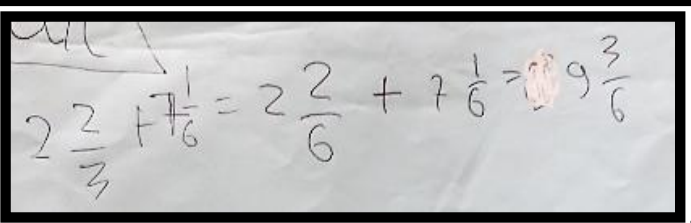

Figure 9b. students 1b's written work in the activity

$$
2 \frac{1}{2}+1 \frac{1}{4}=2 \frac{2}{4}+1 \frac{1}{4}=3 \frac{3}{4}
$$

Figure 9c. students 1c's written work in the activity

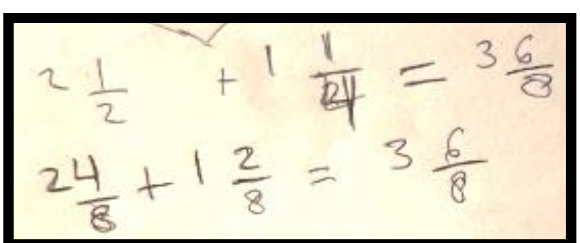

Figure 9d. students 1d' written work in the activity

Figure 10 above shows each students' written work in solving addition of mixed numbers. From the Figure, it can be seen that all the students are able to change the fractions to its equivalence when they add the numbers. However, some of this students still have a difficulty in finding the equivalence of fractions that have the numerator that is not equal to one. Nevertheless, these students are already able to solve and reason what they do in simple addition mixed numbers problems.

\section{students' answer in Second cycle}

In solving the addition of mixed numbers problems, students from second cycle are grouped into 6 groups. Differ from the students in first cycle, some students in the second cycle are unable to find the right strips that should be added. It seems that those students cannot relate what the use of the fractions ruler and strips to the problems that they have to solve. There are several possibility that can explain this. One of those is that the unclear of the instructions given to the students. Nevertheless, most of students are able to find the appropriate strips that they need to use to solve the problems. 
Hening Windria et al., Design Research to Support Fourth Grader Learn Addition ...

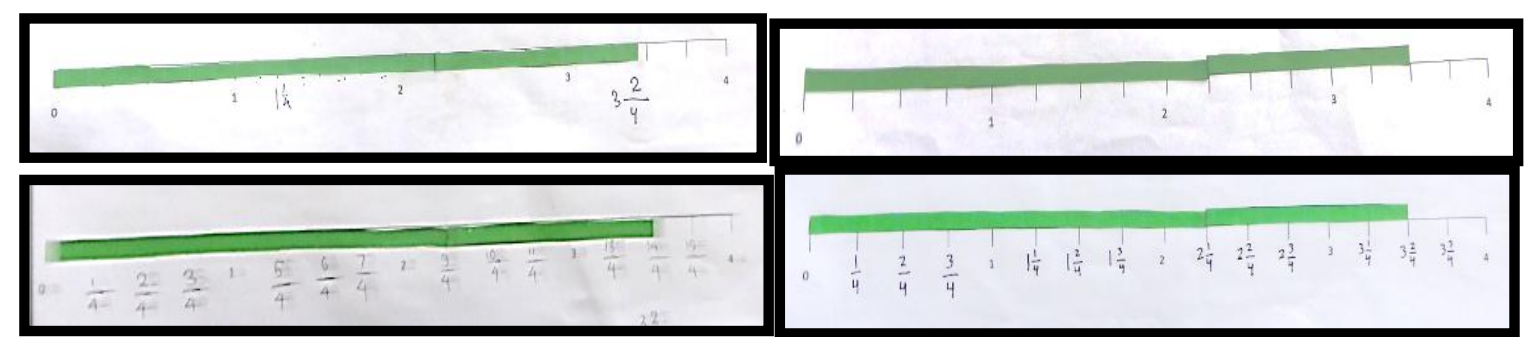

Figure 9. some of students' written work in cycle 2

Figure 9 above shows four of students' written works related to one of the problems in the lesson. From those written work and the interview to the students, at least three of the six groups are using improper fractions to complete the number line. The other three of the groups are using mixed numbers in completing the number line.

Since, both ways of completing the mixed numbers are allowed there is no problem in it. It shows in the answer given by students, they provide two answer, the mixed numbers result and the improper fractions result. However, the focus of the lesson is the result of the mixed numbers, so that students will learn a new method in finding the addition of mixed numbers.

In the discussion sessions, the class will discuss also what have happened to the mixed numbers in the problems. Similar to the discussion in the first cycle, students in the class will also discuss what happen to the fractions in the last problem that is $1 \frac{1}{4}+1 \frac{3}{8}=2 \frac{5}{8}$. Fragment below shows part of the discussion where students try to reason what have happened to the mixed numbers.

Fragment 2 students in second cycle reason about the addition

1. Teacher : it can be seen that (teacher point to the board) it is $1 \frac{1}{4}$ and $1 \frac{3}{8}$, how can the result be $2 \frac{5}{8}$ ?

2. Teacher: Why?

3. Students $2 \mathrm{~g}$ : because..

4. Teacher ; raise your hand

5. Teacher calls one of the students and asks other students to listen to their friend that share his opinion

6. Students $2 \mathrm{~g}$ : because we find the LCM (students refer to the algorithm that they use before in solving addition of fractions that have different denominator)

7. Teacher : LCM of which numbers?

8. Students $2 \mathrm{~g}:$ hmm... (confused)

9. Teacher gives extra time for students to answer the questions

10. Student $2 \mathrm{f} ; \mathrm{hmm}$... it is the LCM of the denominator (it is barely heard)

11. Teacher asking other students why the denominator is changing not according to addition of natural numbers. after a while, when students are not answering her questions, teacher provides the answer 
12. Teacher : according to Bui (students 2f), it is because we find the LCM of the denominator of the fractions part. Do you agree?

13. Class: Agree (chorus)

From this fragment it can be seen that the students are trying to relate the knowledge they already have in learning addition of fractions to reason. Moreover, from the discussion, it is clear that the teacher also stirred the discussion to relate it to the previous algorithm that the students have already learnt. Thus, students' reasons are only related to the algorithm they have received before without any understanding in the reason behind the algorithm. It is very unfortunate indeed.

After this meeting indeed students are able to solve addition of mixed numbers. Most of students are able to solve the addition of mixed numbers problem. The high achiever students in the class prefer to use the method where they change the mixed numbers to improper fractions before adding the numbers (see Figure 10). However, those students are still able to use the other method. On the other hand, the average and the low achiever they tend to use the method where each part of mixed numbers are added separately (see Figure 10).

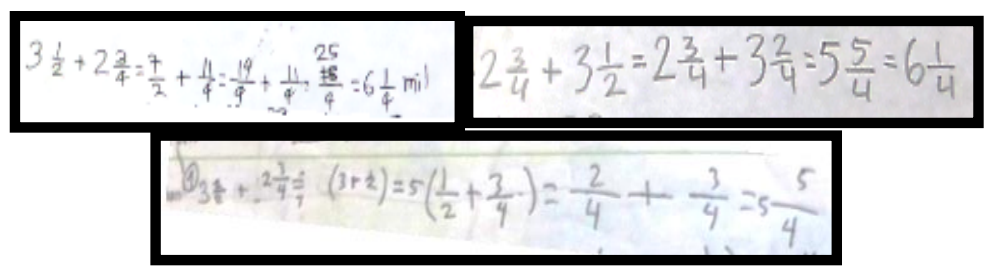

Figure. 10 examples of students' written work in one of lesson after meeting three. From above, high achiever student's written work, average achiever student's written work, and low achiever student's written work

To summarize what had happened in the classroom and what the comparison to the HLT, below are table of the comparison.

Table 1 Comparison of HLT and Actual Learning Trajectory (ALT)

\begin{tabular}{|c|c|c|}
\hline HLT & ALT cycle 1 & ALT cycle 2 \\
\hline $\begin{array}{l}\text { 1. Some students find the } \\
\text { appropriate strips by measuring } \\
\text { the length of the strips using the } \\
\text { fraction ruler. } \\
\text { 2. Some students find the strips } \\
\text { by taking two strips that likely to } \\
\text { be the appropriate one. } \\
\text { 3. Some students not find the } \\
\text { appropriate strips. }\end{array}$ & $\begin{array}{l}\text { In finding the strips } \\
\text { Students are able to find the } \\
\text { appropriate strips by measuring } \\
\text { the length of the strips using the } \\
\text { fraction ruler }\end{array}$ & $\begin{array}{l}\text { 1. Most students are able to find } \\
\text { the appropriate strips by } \\
\text { measuring the length of the } \\
\text { strips using the fraction ruler } \\
\text { 2. Some students are unable to } \\
\text { find the appropriate strips }\end{array}$ \\
\hline $\begin{array}{l}\text { 1. Students are able to find the } \\
\text { result by pasting the } \\
\text { appropriate strips above the } \\
\text { fractions ruler provided. }\end{array}$ & $\begin{array}{l}\text { In finding the result } \\
\text { Students are able to find the } \\
\text { result by pasting the } \\
\text { appropriate strips above the } \\
\text { fractions ruler provided. }\end{array}$ & $\begin{array}{l}\text { 1.Students are able to find the } \\
\text { result by pasting the appropriate } \\
\text { strips above the fractions ruler } \\
\text { provided. }\end{array}$ \\
\hline
\end{tabular}


Hening Windria et al., Design Research to Support Fourth Grader Learn Addition ...

2.Some students are unable to find the correct result since they did not find the appropriate strips.

\section{Completing fraction ruler in order to find the result}

1.Students write all the mixed 1.Students write all the mixed 1.Students write all the mixed numbers correctly in the numbers correctly in the numbers correctly in the appropriate mark appropriate mark appropriate mark

2.Students only write the needed 2.Students only write the needed 2.Students only write the needed mixed numbers, referring to the mixed numbers, referring to the problems

3.Students only write the mixed numbers that is the final result of the problem.
2.Some students are unable to find the correct result since they did not find the appropriate strips. mixed numbers, referring to the problems

3.Students only write the mixed numbers that is the final result of the problem.

4.Students did not write the numbers in the fraction ruler but directly fill the answer by counting the fractions in the ruler.

In reasoning

1. Students are able to use Students are using The students use the formal equivalence reasoning wher equivalence reasoning when algorithmic reasoning explaining what had happen to explaining the mixed numbers

2. Some students might use formal algorithmic reasoning to explain.

Basically, there are two ways of solving addition mixed numbers (Department of mathematics, 2012) as seen in figure 11. The two way of solving addition mixed numbers were appeared in the study. The students from the first cycle, in which they have not learnt addition of fractions beforehand, they chose to use the solution which adding the whole numbers and fractions separately. they also had more understanding in equivalence of fractions. for students in the second cycle, both solutions were appearing in the students' solutions. it is understandable since students in second cycle have already learnt the algorithm to change mixed number to improper fractions.

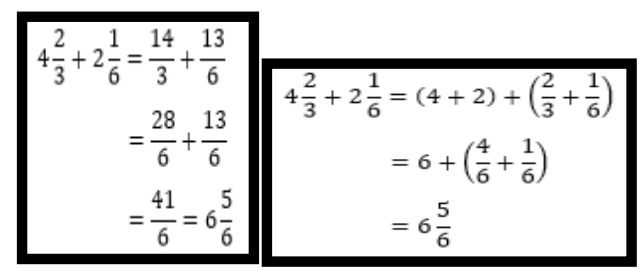

Figure 11. the solution of $4 \frac{2}{3}+2 \frac{1}{6}$ in both method

In addition to the difference in solving the problem, from the table 1 it can be seen that the students in both cycle indeed find their own version of reasoning of what had happen to the mixed numbers in the addition operation. Students from cycle 1 can see the relation between the equivalence and addition of mixed numbers while the students from cycle 2 cannot. The reason behind this possibly lie in the difference of what students have learnt before. Since students in second cycle already learn about addition of fractions using formal algorithm, it is understandable that they will relate the addition of mixed numbers to the algorithm they already know beforehand. Hence, the difference. 
There was also a note from the second cycle students learning process. It seems that the teacher was pointing out the importance of LCM in solving addition of fractions. it might be not a wise move, just like Pantziara and Philippou (2012) stated that students may be able to apply some agorithm, yet they do not understand the conceptual understanding of it. Here, it can be seen that teacher indeed have a great impact for students learning. Similarly, the concept of socio-mathematics norm which refer to what the mathematics is and what the meaning of doing mathematics in particular classroom (Gravemeijer, 2020). Furthermore, to engage students in doing mathematics it is important for the teachers to asking some probing questions (Gravemeijer, 2020). However, as it can be seen for the example of teacher questions in the fragment, it was not a probing question but it is more likely a leading questions. Therefore, it is a no wonder that most students in the second cycle reasoned using an algorithmic and formal reasoning compared to students from the first cycle.

\section{CONCLUSION}

From the result and discussion, it can be seen that most of students are able find the appropriate fractions strips to be used in the measuring processes, even if some of them are not find the appropriate one. Thus, it is understandable that some students arrive in incorrect conclusion for the problems. In time, they would not be able to reason and finding the appropriate conclusion as expected. There are two main reasoning in the addition of mixed numbers. Students from first cycle, yet to learn addition of fractions, opted to use the equivalence of fractions and adding the number and fractions separately. While the students, from the second cycle some of them opted to change the mixed numbers to improper fractions before adding it, while some other are adding the whole number and fractions separately just like what students in first cycle did.

Unfortunately, the role of the fractions strips and fractions number line is not clear. So, it is insufficient to say that the model used here help the students learning addition mixed numbers. Therefore, it can be seen from the results that students were able to build their reasoning in doing addition of mixed numbers. In this sense it can be said that this kind of activity and discussion in classroom can help students in learning addition mixed numbers, especially for students that have not learnt addition of fractions yet. However, it is worth to note that teacher has an important role especially related to what kind of questions should be presented to students.

\section{LIMITATION OF THE STUDY}

Indeed the result of this study still has many limitations. First, this study only used one model of fractions. Fosnot and Dolk (2002) stated that there are many models that can be used to learn fractions. Furthermore, Thompson \& Saldanha (2003) suggested that when students given a freedom to find the most suitable model for them from many models of fractions, themselves, 
Hening Windria et al., Design Research to Support Fourth Grader Learn Addition ...

it can make the model of fractions make sense for them. Second, the problems used in the study only had small number and familiar denominator. Thus, the development of this activity, such as using bigger number in the addition or unfamiliar denominator of the fractions is left open to other researcher to be established in the future.

\section{ACKNOWLEDGEMENT}

A great appreciation is given to Dwi Nuryati, S.Pd. for the participation in the study. Also, colleagues from IMPoME for the time, the advice and critiques when discussed about this study.

\section{REFERENCES}

Bruce, C., Chang, D., \& Flynn, T. (2013). Foundations to Learning and Teaching Fractions: Addition and Subtraction Literature Review.

Departemet of Mathematics. (2012). Prealgebra Textbook. California: College of Redwoods.

Denscombe, M. (2010). The Good Research Guide: For small-scale social research project (5th ed.). London: Mc Graw Hill.

Edelson. (2002). Design Research : what we learn when we engage in Design. Journal of Learning Science, 11(1), 105-121.

Eerde, D. Van. (2012). Design Research : Looking into The Heart of Mathematics Education. In Zulkardi (Ed.), 1st SEA-DR (pp. 1-11). Palembang. Retrieved from http://eprints.unsri.ac.id/2537/

Fosnot, C. T., \& Dolk, M. (2002). Young mathematicians at work. Portsmouth: Heinemann.

Fosnot, C. T. (2007). Field Trips and Introducing Fractions. Portsmouth: Heinemann.

Gravemeijer, K. (2020). A Socio-Constructivist Elaboration. In M. Van den Heuvel-Panhuizen (Ed.), International reflections on the Netherlands didactics of Mathematics (pp. 217233). https://doi.org/10.1007/978-3-030-33824-4

Gravemeijer, K., \& van Eerde, D. (2009). Design Research as a Means for Building a Knowledge Base for Teachers and Teacing in Mathematic Education. The Elementary School Journal, $109,510-524$.

Idris, N., \& Narayanan, L. M. (2011). Error Patterns in Addition and Subtraction of Fractions among Form Two Students. Journal of Mathematics Education, 4(2), 35-54. Retrieved from http://educationforatoz.com/images//dris.pdf

Imm, K. L., Uittenbogaard, W., \& Fosnot, C. T. (2007). Minilessons for Operations with Fractions, Decimals, and Percents A Yearlong Resource. Portsmouth: Heinemann. 
Izsák, A., Tillema, E., \& Tunç-Pekkan, Z. (2008). Teaching and learning fraction addition on number lines. Journal for Research in Mathematics Education, 33-62.

Keijzer, R. (2003). Teaching Formal Mathematics in Primary Education. Amsterdam: Universiteit Amsterdam.

Lestiana, H. T., Rejeki, S., \& Setyawan, F. (2017). Identifying Students' Errors on Fractions. JRAMathEdu (Journal of Research and Advances in Mathematics Education), 1 (2), 131-139.

Niemi, D. (1996). Instructional influences on content area explanations and representational knowledge: Evidence for the construct validity of measures of principled understanding. CSE Technical Report 402.4 Retrieved from http://www.cse.ucla.edu/products/Reports/TECH403.pdf.

Norton, A., \& Wilkins, J. L. M. (2013). Supporting Students' Constructions of the Splitting Operation. Cognition and Instruction, 31(1), 2-28. http://doi.org/10.1080/07370008.2012.742085

Pantziara, M., \& Philippou, G. (2012). Levels of students' "conception" of fractions. Educational Studies in Mathematics, 79(1), 61-83. https://doi.org/10.1007/s10649-011-9338-x

Saxe, G., Taylor, E., Mclntosh, C., \& Gearhart, M. (2005). Representing fractions with standard notation: A developmental analysis. Journal for Research in Mathematics Educations, $36(2), 137-157$.

Sembiring, R., Hadi, S., Dolk, M. (2008). Reforming Mathematics Learning in Indonesian Classroom through RME. ZDM- International Journal on Mathematics Educations, 40, 927939.

Simon, M. A., \& Tzur, R. (2004). Explicating the role of mathematical tasks in conceptual learning: An elaboration of the hypothetical learning trajectory. Mathematical thinking and learning, 6(2), 91-104.

Tanton, J. (2005). Encyclopedia of Mathematics. New York: Facts on File.

Thompson, P. W., \& Saldanha, L. A. (2003). Fractions and multiplicative reasoning. Research companion to the principles and standards for school mathematics, 95-113.

Weisstein, E. W. (2003). CRC Concise Encyclopedia of Mathematics (2nd ed.). Boca Raton, London, New York, Washington D.C.: chapman \& Hall/ CRC. 
Hening Windria et al., Design Research to Support Fourth Grader Learn Addition ...

Zulkardi. (2002). Developing a learning environment on Realistic Mathematics Education for Indonesian student teacher (Doctoral Dissertation). University of Twente: Enskede. (available online at http://doc.utwente.nl/58718/1/thesis_Zulkardi.pdf) 